\title{
RESGATE CONCEITUAL DE ACCOUNTABILITY: PROPOSTA DE CATEGORIZAÇÃO A PARTIR DE ESTUDO BIBLIOMÉTRICO
}

\author{
CONCEPTUAL RESCUE OF ACCOUNTABILITY: \\ PROPOSED CATEGORIZATION FROM BIBLIOMETRIC STUDY
}

ANDRÉ LUÍS FARIA DUARTE

Universidade do Grande Rio - UNIGRANRIO

Titulação: Mestre em Administração (UNESA)

Analista em C\&T na CNEN

Doutorando em Administração na UNIGRANRIO

Orcid: http://orcid.org/0000-0002-9862-6225 / e-mail: alduarte@cnen.gov.br

Endereço: Rua Gal. Severiano, 72 / sl. 411, Botafogo, Rio de Janeiro, RJ

\author{
DEBORAH MORAES ZOUAIN \\ Universidade do Grande Rio - UNIGRANRIO \\ Titulação: Doutora em Engenharia de Produção (COPPE/UFRJ) \\ Professora do PPGA/UNIGRANRIO \\ Orcid: http://orcid.org/0000-0003-4813-9741 / E-mail: deborahzouain@gmail.com
}

\section{RESUMO}

Accountability é uma palavra cada vez mais utilizada e debatida em variados contextos, tanto na academia quanto na sociedade em geral, sendo exaustivamente discutido seu significado. Nesse sentido, o presente estudo procura explorar a forma como tem sido pesquisado o conceito e a prática da accountability, a partir de um resgate sobre como se entende esse conceito em variados contextos históricos, bem como propor uma definição e uma categorização que sintetize as várias tipologias já encontradas na literatura. Para tal, foi realizado estudo com técnicas de bibliometria e de análise de conteúdo com dezesseis obras selecionadas que apresentam variadas categorizações para o estudo da accountability. Apesar da indefinição do conceito de accountability, que não ocorre apenas em língua portuguesa, é proposta uma definição abrangente, que possa ser aplicada nos mais variados contextos. Como síntese das tipologias encontradas na literatura, são propostas cinco categorias de accountability: Política, Legal, Mútua, Hierárquica e Profissional.

Palavras-chave: Accountability. Categorização. Literatura científica. Bibliometria. Análise de citação .

\begin{abstract}
Accountability is a word increasingly used and debated in various contexts, both in academia and in society in general, and its meaning is thoroughly discussed. In this sense, the present study seeks to explore the way in which the concept and practice of accountability has been researched, starting from a rescue about how this concept is understood in various historical contexts, as well as to propose a categorization that synthesizes the various typologies already found. in literature. To analyze approaches that use accountability categorizations to study this phenomenon. To this end, a study was conducted using bibliometrics and content analysis
\end{abstract}


techniques with sixteen selected works that present different categorizations for the study of accountability. The final considerations of the article indicate that the definition of accountability has been a matter debated in several forums, without reaching a consensus. This issue occurs not only in Portuguese but also in other languages. As a synthesis of the typologies found in the literature, five categories of accountability are proposed: Political, Legal, Mutual, Hierarchical and Professional.

Keywords: Accountability. Categorization. Scientific literature. Bibliometry. Citation analysis.

\section{INTRODUÇÃO}

Um dos temas muito estudados recentemente na academia e que tem tido grande relevância nos fóruns e debates da área de administração com ênfase na administração pública, é a accountability, que de acordo com Xavier (2011), trata-se de um tema complexo, multidisciplinar e multidimensional. Accountability é uma expressão da língua inglesa que se refere a conceitos como transparência, prestação de contas e responsabilização. Tais conceitos são fundamentais para as democracias representativas modernas, cujas atividades governamentais "devem estar circunscritas pelas leis e desenvolverem-se dentro dos limites dos interesses democráticos e sociais" (ROCHA, 2013, p. 904). De acordo com Olsen (2018, p. 25), "nas democracias representativas contemporâneas, a accountability é vista como um ideal e uma conquista, assim como parcialmente constitutiva do governo democrático".

Não há consenso sobre a tradução de Accountability para o português. De acordo com Campos (1990), aos brasileiros não falta precisamente a palavra, mas sim o conceito de accountability, cujo exercício "é determinado pela qualidade das relações entre governo e cidadão, entre burocracia e clientelas" (CAMPOS, 1990, p. 35). No entanto, a indefinição da questão ontológica da accountability não ocorre apenas no Brasil. Bovens (2010) sustenta que grande parte da literatura sobre accountability é desconectada, com muitos autores produzindo sua própria definição específica. Esse autor afirma que qualquer um que estude accountability logo descobre que esse conceito pode significar muitas coisas diferentes para muitas pessoas diferentes, sendo usado como sinônimo para muitos objetivos políticos vagamente definidos, como a boa governança, transparência, equidade, democracia, eficiência, agilidade, responsabilidade e integridade (BOVENS, 2010). Para Cumbe e Inácio (2018), accountability tornou-se um conceito maleável e muitas vezes nebuloso, com conotações que mudam de acordo com o contexto e os interesses.

Hall, Frink e Buckley (2017) sustentam que a accountability está ainda em estágio incipiente como domínio de pesquisa acadêmica, havendo ainda muito desconhecimento sobre esse importante e complicado construto. Para Rocha (2011), tanto a prática quanto o conceito de accountability são questões novas na nossa sociedade, necessitando, portanto, de mais pesquisas na área. Em análise sobre como o termo accountability é tratado na literatura acadêmica brasileira, Medeiros, Crantschaninov e Silva (2013) afirmam que a accountability está relacionada principalmente às ideias de responsabilidade e prestação de contas.

Em função desta grande indefinição acerca do conceito de accountability, o presente estudo se propõe a responder a questão de como são categorizadas, na literatura, as diferentes abordagens de accountability para que esse fenômeno seja estudado, bem como quais são as características dessas pesquisas. Portanto, o objetivo da pesquisa é, a partir da identificação das diversas abordagens de accountability e análise das características desse 
conjunto de obras, propor uma definição do conceito, bem como uma categorização que represente a síntese desses estudos, contemplando todas as abordagens já pesquisadas.

A contribuição que se pretende com o estudo, além de propor uma nova categorização e uma definição que sejam uma síntese do que já se encontra na literatura, é discutir o conceito de accountability a partir dos diversos estudos que buscaram analisar esse construto.

\section{FUNDAMENTAÇÃO TEÓRICA}

Os países ocidentais, de acordo com Filgueiras (2011), têm vivenciado uma crescente demanda por accountability, que vem sendo considerada por diferentes tradições de pensamento, de fundamental importância à democratização do Estado. Ackerman (2004) sustenta que um bom governo não surge espontaneamente a partir dos bons corações de burocratas e políticos, mas que é o resultado de um processo difícil de design institucional, sendo a accountability o principal elemento garantidor de um bom governo. Nesse sentido, Ceneviva (2006) ressalta que accountability não é um predicado dos sujeitos, mas um atributo do sistema político que se impõe aos agentes públicos, sejam governantes ou burocratas.

A questão epistemológica dos estudos de accountability parece ainda mais nebulosa, na medida em que o próprio conceito não é bem definido. Ceneviva (2006) argumenta que normalmente é aceita a ideia de que accountability está relacionada a controle e fiscalização de agentes públicos, o que não ocorre quando se tenta delimitar seus objetos, sujeitos, meios e escopo. Graciliano et al. (2010) enfatizam que accountability é um tema que ganhou importância quando se analisa a qualidade das organizações nas sociedades democráticas modernas. As organizações têm enfrentado expectativas crescentes de accountability (BUSUIOC; LODGE, 2017), que tem sido um elemento fundamental de todas as sociedades e das organizações que operam dentro delas (HALL; FRINK; BUCKLEY, 2017).

A temática de accountability, principalmente no Brasil, tem sido fortemente relacionada às questões de Estado e governo, estando grande parte da produção acadêmica nas áreas da administração pública, ciência política e afins. Como exemplo, Campagnoni et al. (2016. p. 24) afirmam que accountability "pode ser entendida por uma noção de explicação e responsabilização que um gestor público deve prestar e estar sujeito em relação à sociedade", ainda que seja um termo cujo entendimento seja alterado em função de valores e suposições. Já para Bernardes, Santos e Rover (2015, p. 774), "a accountability demanda um efetivo empowerment (empoderamento) dos cidadãos, de modo a permitir que eles transformem todas as informações em conhecimento e atuem no processo de coprodução de políticas públicas". De acordo com Bouwman et al. (2018), a accountability é muitas vezes vista como um instrumento para prevenir a corrupção daqueles que estão no poder, e também como um mecanismo de controle democrático que supostamente aumenta o desempenho, melhora a integridade da governança pública e rende percepções de confiabilidade e transparência com os cidadãos.

Accountability tem a ver com o fato de que, para a devida observância de regras e regulamentos, aqueles que administram as regras devem ser responsabilizados por suas ações (MYINT, 2000). Para Papenfuß e Schaefer (2010), a consideração da literatura sobre gestão pública e governança pública e corporativa revela que a teoria da agência é uma perspectiva teórica dominante para ilustrar e analisar a accountability. Essa teoria permite que a relação de accountability entre o principal (cidadão) e os agentes (políticos, administração, gestores públicos) seja descrita de forma mais adequada. Nesse sentido, a accountability é derivada da linha de argumentação de que o eleitorado tem o direito de ser informado sobre as atividades e os gastos de recursos pelo executivo e pelo legislativo (PAPENFUß; SCHAEFER, 2010). "Nas 
abordagens principal-agente, o elemento central dos processos de accountability é a tomada de decisão, em que os atores racionais demandam, processam, avaliam e sancionam a prestação de contas com base no cálculo da vantagem esperada" (OLSEN, 2018, p. 46).

No contexto de agências regulatórias, Koop e Hanretty (2018) acreditam que a accountability serve a mais propósitos do que aumentar a qualidade da tomada de decisões regulatória, até porque, estudos não apontam inequivocamente para um efeito positivo da accountability no desempenho. A accountability também está associada a custos excessivos e burocracia. Para esses autores, a accountability política é crucial para a legitimidade democrática (KOOP; HANRETTY, 2018).

Sinclair (1995) ressalta a importância da linguagem como agente da ideologia na formação da compreensão do conceito de accountability, enfatizando que na pesquisa teórica, accountability tem significados específicos a cada disciplina, como os auditores que discutem accountability como se fosse uma questão financeira ou numérica, cientistas políticos que a consideram um imperativo político, os juristas como um arranjo constitucional, enquanto os filósofos a tratam como um subconjunto da ética. Boa parte dos estudos do tema baseia-se na classificação ou categorização, enfocando diferentes abordagens de accountability, que buscam estabelecer parâmetros para que se pesquise o fenômeno, levando em conta o contexto político, social, histórico, cultural, dentro outros.

\subsection{ACCOUNTABILITY NA PERSPECTIVA HISTÓRICA}

Encontram-se na literatura vários estudos que identificam práticas de accountability nos mais variados períodos históricos. Para Carmona e Ezzamel (2007), em civilizações antigas, como na Mesopotâmia e no antigo Egito, existiam três esferas de accountability: de indivíduo para indivíduo; de indivíduo para o estado e do estado para o indivíduo.

De acordo com Soll (2014), na antiga Atenas havia accountability, que consistia em um complexo sistema de contabilidade e auditoria pública no coração do governo democrático. Godfrey e Hooper (1996) argumentam que o levantamento feito na Inglaterra medieval finalizado em 1086, registrado no que é conhecido como Domesday Book, foi mais do que um cadastro fiscal, pois permitiu ao rei Guilherme I, mensurar as riquezas, aumentar os impostos e distribuir recursos dentro da estrutura feudal que ele havia estabelecido, tendo características de accountability. Thick (1999) analisou os livros utilizados na cidade de Southampton no século XV e considerou que a cidade estava bem ciente da importância da accountability e do valor de uma boa informação financeira como um meio de controle.

A Revolução Francesa, de acordo com Soll (2014) começou, de certa forma, como uma luta sobre a accountability do governo, e conseguiu introduzir uma cultura de educação financeira e accountability na política, que foram as sementes para futuras reformas contábeis. No artigo XV da Declaração dos Direitos do Homem e do Cidadão de 1789, por exemplo, consta que a sociedade tem o direito de solicitar a prestação de contas de qualquer agente público. Para Bryer (2000), as diferentes relações de poder sob o feudalismo e o capitalismo refletiram-se em diferentes formas de accountability, pois a accountability feudal considerava a existência de agentes do senhor feudal, sendo os camponeses pessoalmente responsáveis por prestar contas ao senhor, enquanto que no capitalismo o lucro vem do trabalho assalariado e é distribuído proporcionalmente ao capital investido por cada capitalista, sendo a administração responsável perante o capital para estipular a taxa de retorno sobre o capital empregado na produção. Desta forma, a história da accountability demonstra a transição do controle político do feudalismo para o controle econômico do capitalismo (BRYER, 2000). 
O conceito de accountability expandiu-se, segundo Bevir (2011), ao longo do modernismo. Para esse autor, o modernismo associava-se à descrença no progresso das nações rumo ao Estado organizado, à liberdade e ao governo responsável, mas também deu origem a novas formas de ciências sociais, que se desenvolveram com vistas a fornecer um conhecimento técnico supostamente neutro, que orientaria a formulação de políticas que produziriam melhores resultados, ajudando a manter a distinção entre política e administração (BEVIR, 2011). Neste sentido, Cumbe e Inácio (2018) afirmam que accountability é um termo que surgiu na sociedade democrática moderna.

Os resgates históricos acerca da utilização do conceito de accountability demonstram um lado da trajetória de discussão ontológica e epistemológica do assunto. Evidentemente o conceito de accountability empregado em cada período histórico é único e carrega suas próprias características. No entanto, é importante perceber que a ideia de accountability e os conceitos relacionados a ela já permeia há muito tempo o pensamento e as discussões nos planos econômicos, sociais, históricos e políticos.

Na contemporaneidade, principalmente a partir dos anos 1980, a importância da accountability aumentou significativamente. Antes de 1960, de acordo com Martin e Frahm (2010), o conceito de accountability na prática da administração recebia menor atenção, provavelmente em função de uma certa credibilidade na responsabilidade profissional dos administradores e funcionários públicos, que reduzia a percepção da necessidade de incorporar regularmente a accountability na prática administrativa.

$\mathrm{Na}$ área privada a accountability também se expandiu, tanto em organizações sem fins lucrativos, que eventualmente tem perfil e atuação mais parecidos com as organizações da área pública, como também em empresas com fins lucrativos. Nesse sentido, em 2004 foi editado pelo International Federation of Accountants (IFAC) um trabalho que defende o conceito de plena accountability, focando o desempenho econômico-financeiro do negócio e a conformidade da contabilidade da empresa à legislação que regula suas atividades (NAKAGAWA; RELVAS; DIAS FILHO, 2007). De acordo com Mulgan (2000), as preocupações com a accountability do setor privado se refletem na recente evolução do direito administrativo e na jurisprudência.

\section{METODOLOGIA}

A pesquisa utiliza abordagem qualitativa e se caracteriza, quanto aos fins, como estudo descritivo, pois se propõe a descrever as características de determinado fenômeno, e exploratório, pois tem o propósito de proporcionar familiaridade com um problema (GIL, 2008), qual seja, o das várias classificações de accountability encontradas na literatura. Quanto aos meios, pertence ao grupo de pesquisas bibliográficas, realizada a partir de ampla pesquisa na literatura científica, de trabalhos publicados sobre accountability, que tenham proposto algum tipo de categorização. Foram utilizadas técnicas de bibliometria e de análise de conteúdo como meio de viabilizar inferências acerca do contexto em que os estudos foram realizados, permitindo, dessa forma, uma visão mais abrangente dos artigos e suas categorizações. A análise de conteúdo é utilizada, portanto, de modo interpretativo, no contexto de uma abordagem qualitativa (GRANEHEIM; LINDGREN; LUNDMAN, 2017). Foi feita, também, análise de citação dos artigos estudados, onde se buscou identificar as obras mais citadas e os artigos bibliograficamente acoplados (ZUPIC; ČATER, 2015).

Para tal, foram selecionados na base do Google Acadêmico, trabalhos que discutem formas de accountability em diferentes momentos históricos, e ainda dezesseis artigos sobre 
o tema, publicados a partir da década de 1980, de diferentes autores, países e instituições que apresentam variadas categorizações para o estudo da accountability.

A seleção dos artigos foi feita a partir da busca das expressões "classificação de accountability", "categorização de accountability" e "tipologia de accountability", tanto em inglês quanto em português. Foi feita também seleção pelo método "bola de neve", no qual um artigo é selecionado a partir de sua citação em outro artigo analisado.

O Google Acadêmico tem sido utilizado cada vez mais como uma base de dados abrangente, já tendo diversos estudos recentes que comparam essa base com outras já estabelecidas, principalmente a base Scopus e a Web of Science (PRINS et al., 2016; SILVA; GRÁCIO, 2017; MARTÍN-MARTÍN et al., 2018; GUSENBAUER, 2019; DABÓS; GANTMAN; RODRÍGUEZ, 2019).

\section{CATEGORIZAÇÕES DE ACCOUNTABILITY}

Conforme já citado, grande parte dos estudos que abordam accountability se baseia em categorização ou classificação, com o intuito de melhor entender as várias dimensões deste conceito e suas aplicações. São apresentadas, a seguir, algumas dessas categorizações.

\subsection{SMITH E A ADMINISTRAÇÃO PÚBLICA BRITÂNICA}

Uma das primeiras classificações de accountability encontrada na literatura foi proposta por Smith (1981) e refere-se a um estudo acerca da administração pública britânica, sendo bastante focada nessa realidade. Esse autor classificou a accountability em nove tipos: constitucional, judicial, consultiva, quase judicial, processual, econômica, comercial, profissional e descentralizada. Para ele a Accountability constitucional relaciona-se ao fato de o chefe político ter que responder aos representantes eleitos da nação pelas ações e decisões de seus funcionários. O político deve ser o responsável em caso de mau funcionamento administrativo na execução da política pública.

A Accountability judicial, segundo o autor, parte do princípio fundamental de que as decisões e ações dos funcionários nos departamentos governamentais devem ter embasamento legal. Dessa forma, um departamento não deve exceder suas responsabilidades e deve fazer o que é obrigado a fazer, seguindo os procedimentos prescritos sem negligência, irracionalidade ou má-fé (SMITH, 1981). Já a Accountability consultiva relaciona-se à prática de consultar as partes interessadas e outros interesses afetados no curso da formulação das políticas, ou seja, a sociedade organizada sabe que deve ser consultada e o governo sabe que deve consultar.

Accountability quase-Judicial refere-se à necessidade de interpretação das leis e normas que especificam direitos e deveres a determinados indivíduos, desde que cumpram algumas condições, e o departamento ou instância responsável precisa decidir se um caso particular se enquadra dentro de uma categoria à qual certas regras se aplicam. A accountability processual está relacionada ao critério da razoabilidade, ou seja, os procedimentos administrativos e excesso de burocracia não devem causar dificuldades ou injustiças quando aplicados a casos individuais. Torna-se uma questão de identificar o uso irracional e abusivo de autoridade (SMITH, 1981).

Accountability econômica envolve, de acordo com Smith (1981), o planejamento e gestão dos recursos com base na preocupação de que os recursos públicos só devem ser gastos em projetos autorizados e controlados pelo parlamento, no sentido de eliminar desperdícios e incentivar boas práticas de orçamento, contratos e administração financeira 
em geral. Accountability comercial parte da liberdade das empresas públicas em tomarem decisões comerciais em resposta às pressões do mercado. Elas operariam a uma distância do controle ministerial e parlamentar para garantir a liberdade comercial. No entanto, de acordo com Smith (1981), o conselho de administração de cada empresa deve atuar como custodiante do interesse público.

Accountability profissional, para Smith (1981), refere-se ao que se chama de "propriedade do conhecimento". O desenvolvimento e implementação de políticas públicas tornaram-se cada vez mais dependentes das contribuições de cientistas, tecnólogos e outros grupos profissionais, sendo importante que se tenha a perspectiva técnica/profissional, além do nível político. A Accountability descentralizada refere-se à suposição de que alguns serviços públicos são melhor prestados localmente por funcionários públicos responsáveis pelo todo do que por representantes eleitos localmente responsáveis por uma área limitada. (SMITH, 1981).

\subsection{ROMZEK E DUBNICK E A TRAGÉDIA DA CHALLENGER}

Outra classificação de accountability foi proposta Romzek e Dubnick (1987), a partir da investigação do acidente do ônibus espacial Challenger. Esses autores sustentam que o acidente foi, em parte, uma manifestação dos esforços da NASA para gerir as diversas expectativas que enfrenta no sistema político. Para esses autores, quatro tipos de accountability são comumente utilizados por órgãos públicos para gerenciar suas expectativas: burocrática, legal, profissional e política. Essa classificação surge com base nas variações de dois fatores críticos: 1) se a capacidade de definir e controlar expectativas é mantida por alguma entidade especificada dentro ou fora da agência; e 2) o grau de controle sobre as ações das agências. As interações dessas duas dimensões geram os quatro tipos de sistemas de accountability propostos pelos autores (ROMZEK; DUBNICK, 1987).

Sistemas de accountability burocrática são mecanismos amplamente utilizado para gerenciar as expectativas de órgãos públicos. Segundo esta abordagem, as expectativas dos administradores públicos são geridas com atenção às prioridades dos que estão no topo da hierarquia burocrática. A accountability legal, para Romzek e Dubnick (1987), é semelhante à burocrática, mas é baseada no relacionamento entre a parte controladora fora da agência. Normalmente, um indivíduo ou grupo tem condições de impor sanções legais ou afirmar obrigações contratuais formais e o administrador público é obrigado a cumprir ou implementar.

Accountability profissional ocorre com maior frequência quando os governos lidam com problemas tecnicamente difíceis e complexos. Nessas circunstâncias, Romzek e Dubnick (1987) sustentam que os funcionários devem contar com profissionais qualificados e especializados para fornecer soluções adequadas. Assim, é caracterizada pela colocação de controle sobre as atividades nas mãos do trabalhador com experiência ou habilidades especiais para fazer o trabalho. Já na accountability política, a questão principal é: "Quem o administrador público representa?" Os círculos eleitorais potenciais incluem o público em geral, funcionários eleitos, chefes de agências, agência clientela, outros grupos de interesses especiais, e as gerações futuras (ROMZEK; DUBNICK, 1987). 


\subsection{O'DONNELL E A DEMOCRACIA DELEGATIVA}

Uma outra classificação pioneira, e também uma das mais reconhecidas e citadas na literatura, é proposta por O'Donnell $(1991 ; 1998)$ em seus estudos sobre democracia, que divide as formas de accountability em duas: a) vertical e b) horizontal.

De acordo com essa classificação, ações individuais ou coletivas de fiscalização ou controle sobre quem ocupa posições no âmbito de instituições do Estado, eleitos ou não, é considerada accountability vertical. O caso característico dessa forma de accountability é o processo eleitoral, mas também se incluem as consultas públicas, ações e reivindicações da sociedade civil e a cobertura da mídia dessas ações. Já uma rede de poderes relativamente autônomos, as instituições de controle e fiscalização, como as agências reguladoras e o tribunal de contas, que têm o poder de fiscalizar outros órgãos governamentais caracterizam a accountability horizontal (O'DONNELL, 1991; 1998).

\subsection{KEARNS E A GESTÃO ESTRATÉGICA DE ACCOUNTABILITY EM ORGANIZAÇÕES SEM FINS LUCRATIVOS}

Kearns (1994) propõe um quadro conceitual que evidencia quadro dimensões de accountability em organizações sem fins lucrativos. Para esse autor, um sistema de accountability contém pelo menos duas dimensões: um conjunto de padrões de desempenho - explícito ou implícito - gerado pelo ambiente estratégico da organização; e uma resposta reativa ou proativa - a partir do interior a organização. Padrões explícitos são aqueles geralmente codificados em lei, regulamentos administrativos e obrigações contratuais. Normas implícitas envolvem noções gerais de ação administrativa e comportamento organizacional. Por sua vez, a resposta da agência a essas normas pode ser reativa (tática) ou proativa (estratégica). Desta forma, a partir do entrelaçamento dessas duas dimensões, são identificados quatro tipos de accountability: a) da conformidade (Compliance); b) negociada

(Negotiated); c) discricionária/profissional (Professional/discretionary); e d) antecipatória/posicionada (Anticipatory/positioning).

A accountability da conformidade refere-se à forma mais familiar de accountability em uma organização sem fins lucrativos, com uma norma de desempenho ou procedimento operacional explícito imposto e executado em conformidade com a sua própria regra e procedimentos operacionais. Já a accountability negociada aborda contextos em que as normas estão implícitas, decorrentes de mudança de valores e crenças da sociedade ou das tendências políticas que ainda não foram codificadas na lei ou regulamentos administrativos.

A accountability discricionária/profissional retratao contexto em que os padrões de desempenho são implícitos, porém a organização responde com estratégias proativas, em vez de táticas de negociação reativa. Na accountability antecipatória/posicionada a organização enfrenta a perspectiva de padrões de desempenho explícitas impostas a partir do exterior, mas os administradores procuram antecipar a formulação destas normas, a fim de posicionar a organização para eventual conformidade (KEARNS, 1994).

\subsection{SINCLAIR E O CONCEITO “CAMALEÃO” DE ACCOUNTABILITY}

Sinclair (1995) realizou pesquisa na qual entrevistou 15 executivos de organizações australianas do setor público e identificou cinco formas de accountability: política, pública, gerencial, profissional e pessoal.

O conceito de accountability política decorre das tradições democráticas atenienses e de Westminster de atribuir responsabilidades ao servidor público, que exerce autoridade em 
nome de representantes eleitos. A accountability política não é entendida como uma cadeia, mas como um baluarte legitimador contra a interferência na administração do órgão e como um freio ao órgão público que se desvia para os assuntos políticos. Os executivos invocam a accountability política como uma rede de segurança para os administradores quando a política ameaça intrometer-se, já que os mantém dedicados às atividades administrativas (SINCLAIR, 1995).

Já a accountability pública é entendida como mais informal e direta em relação ao público, grupos comunitários e indivíduos. Envolve responder, através de vários mecanismos, desde relatórios de jornais a audiências, preocupações públicas sobre a atividade administrativa. A accountability gerencial é vista como focada no monitoramento de insumos e produtos ou resultados. Pode ser entendida como parte de um contrato, que abdicará se o lado político do contrato for violado. O executivo é responsável pela realização dos objetivos dentro do prazo e dentro do orçamento (SINCLAIR, 1995).

A accountability profissional invoca o senso de dever que se tem como membro de um grupo profissional ou de especialistas, que por sua vez ocupa uma posição privilegiada na sociedade. A accountability pessoal é a fidelidade à consciência pessoal em valores básicos. Baseia-se na crença de que, em última instância, a accountability é impulsionada pela adesão aos valores morais e éticos internos e morais (SINCLAIR, 1995).

\subsection{KALDOR E A SOCIEDADE CIVIL}

Kaldor (2003) aborda a questão da accountability em relação à sociedade civil de uma forma geral, incluindo movimentos sociais, organizações não governamentais (ONG), grupos religiosos e nacionalistas. São definidas as seguintes: a) accountability moral - também chamada de externa ou estratégica; e b) accountability procedimental - também chamada de interna, funcional ou gerencial.

Accountability moral pede ser entendida como a accountability de uma organização em relação às pessoas que ela ajuda, ou seja, é a medida do quanto a ONG se mantém fiel à sua missão. Já accountability procedimental está relacionada à prática da gestão interna. Kaldor (2003) argumenta que a contradição entre accountability moral e processual aplica-se principalmente às ONGs e questiona o quanto accountability moral ajuda a garantir a accountability procedimental.

\subsection{GOODIN E A ACCOUNTABILITY NO TERCEIRO SETOR}

Goodin (2003) pesquisou as particularidades do terceiro setor, classificando accountability a partir de duas dimensões: a dimensão do objeto e a dimensão do mecanismo. O objeto da accountability refere-se ao que as pessoas são responsáveis, ou seja, o que elas precisam explicar no âmbito da accountability. Em que termos uma explicação aceitável deve ser formulada? Nesse sentido, existem genericamente três tipos distintos de coisas consideradas objetos da accountability: ações, resultados e intenções (GOODIN, 2003).

De acordo com Goodin (2003), as ações referem-se ao que é ou foi realizado. Se a ação está dentro da lei ou dentro das legítimas prerrogativas. Os resultados referem-se às consequências do que foi realizado, ou seja, se o que foi feito produziu bons efeitos. Já as intenções referem-se ao motivo de se realizar algo. Por quê foi/será feito o que foi/será feito. Quais os motivos? Que resultados são esperados?

Já em relação aos mecanismos de accountability, estes se referem aos dispositivos ou ferramentas que servem para garantir o que quer que seja (ações, resultados ou intenções). 
Goodin (2003) sustenta que qualquer sistema de accountability real costuma empregar uma mistura de mecanismos. Mas genericamente parece haver três mecanismos distintos: a) sistemas hierárquicos de comando e controle; b) disciplina competitiva do mercado e dos sistemas cognatos de controle social; e c) por meio de redes de cooperação, acompanhamento e sanção.

O primeiro mecanismo de accountability, para Goodin (2003), se caracteriza por uma relação de autoridade. Subordinados são responsáveis perante seus superiores, que por sua vez, são responsáveis perante seus próprios superiores. O segundo mecanismo de accountability opera através do choque de interesses e perspectivas, de modo a garantir que os bons resultados aconteçam. Se a accountability é para o bem comum, como o mercado supostamente pretende ser, a concorrência precisa ser protegida por leis confiáveis. 0 terceiro mecanismo de accountability funciona entre uma rede de co-elementos que partilham cultura comum de normas, valores, metas e princípios semelhantes. São realizados ajustes mútuos e as normas não têm caráter instrumental, já que os valores são internalizados e compartilhados.

Desta forma, a tese central de Goodin (2003) é de que a accountability do setor estatal, ou setor público, se concentra nas ações como objeto e nas estruturas de autoridade hierárquicas como mecanismo para alcançar a accountability. Já a accountability de mercado, caracterizado pela iniciativa privada, se concentra nos resultados como objeto e baseia-se na competição como mecanismo. Por fim, o setor sem fins lucrativos, também chamado de terceiro setor, foca nas intenções enquanto objeto e predomina o controle mútuo de cooperação como mecanismo característico para a accountability.

\subsection{ABRUCIO E LOUREIRO E A ACCOUNTABILITY DEMOCRÁTICA}

Outra categorização encontrada na literatura é a proposta por Abrucio e Loureiro (2004) que tem foco no setor público, mais especificamente nas finanças públicas. Esses autores partem de três princípios orientadores de ideais democráticos que correspondem a tipos de accountability democrática. Desta forma, a accountability pode ser dividida em três formas: processo eleitoral, controle institucional durante o mandato e regras estatais intertemporais.

O processo eleitoral corresponde ao princípio democrático da soberania popular em escolher seus governantes e é uma questão básica de qualquer governo democrático. 0 controle institucional durante o mandato relaciona-se ao princípio de que os governantes devem prestar contas ao povo e se responsabilizar por seus atos. O controle parlamentar do poder legislativo sobre o executivo é um exemplo dessa categoria. No entanto, para esses autores, o grande destaque no controle institucional durante o mandato refere-se aos instrumentos de controle direto da sociedade, como consultas populares por meio de plebiscitos e conselhos consultivos e deliberativos. Regras estatais intertemporais relacionamse aos limites de atuação dos governantes e garantia das liberdades individuais e coletivas. No Brasil, de acordo com Abrucio e Loureiro (2004), as cláusulas pétreas da constituição federal procuram garantir essas regras.

\subsection{KOPPELL E A DESORDEM DAS MÚLTIPLAS ACCOUNTABILITIES}

Outra classificação foi proposta por Koppell (2005), que desenvolveu uma tipologia com o objetivo de facilitar as discussões sobre accountability, sendo classificadas cinco categorias não excludentes. Esse autor argumenta que as expectativas conflitantes da 
accountability contribuem com a disfunção organizacional na administração pública. No lugar de satisfazer todas as concepções de accountability, a organização, muitas vezes, não satisfaz nenhuma. As categorias são: transparência (transparency), sujeição (liability), controle (controllability), responsabilidade (responsibility) e responsividade (responsiveness). Os dois primeiros tipos (transparência e sujeição) podem ser considerados como fundamentos, apoiando noções que sustentam a accountability em todas as suas manifestações. Para cada categoria há uma pergunta considerada a extensão prática do conceito.

Para Koppell (2005), a transparência é o valor básico e literal da accountability, a ideia de que um burocrata e organização devem explicar suas ações. Uma organização pública transparente permite acesso ao público, imprensa, grupos de interesse e outros stakeholder. Nessa categoria a pergunta que se procura responder é "A organização revela os fatos relacionados ao seu desempenho?". A categoria da sujeição atribui culpabilidade à transparência. Nessa visão, indivíduos e organizações devem ser responsabilizados por suas ações, punidos por malfeitorias e recompensados pelo sucesso. Procura responder a seguinte pergunta: "A organização assume as consequências pelo seu desempenho?". O controle refere-se ao fato dos funcionários eleitos devem chegar a um consenso sobre os objetivos de políticas públicas e confiar nos burocratas para implementar suas políticas escolhidas. A pergunta prática é: "A organização faz o que o principal (Congresso, presidente) deseja?". Na responsabilidade, burocratas e organizações podem ser limitados por leis, regras e normas. Pode também assumir a forma de padrões profissionais formais e informais ou normas comportamentais. A pergunta prática nesse caso é: “A organização segue as regras?". Por fim, a responsividade refere-se à capacidade de resposta da organização. A pergunta prática é: "A organização cumpre as expectativas (demanda/necessidade)?" (KOPPELL, 2005).

\subsection{GRANT E KEOHANE E O ABUSO DE FORÇA NA POLÍTICA GLOBAL}

Com objetivo de identificar oportunidades para melhorar as proteções contra os abusos de poder no nível global, Grant e Keohane (2005) identificaram sete tipos de accountability: hierárquica, supervisora, fiscal, legal, de mercado, por pares e de reputação pública.

Accountability hierárquica é uma característica das burocracias e de praticamente toda grande organização, incluindo organizações multilaterais como as Nações Unidas ou o Banco Mundial. Accountability supervisora refere-se às relações entre organizações onde uma organização age como principal em relação a agentes específicos. Por exemplo, o Banco Mundial e o FMI estão sujeitos à supervisão dos Estados e suas instituições, como os tribunais (GRANT; KEOHANE, 2005).

Accountability fiscal descreve mecanismos por meio dos quais as agências de financiamento exigem relatórios e sancionam os beneficiários do financiamento. Esta forma de accountability foi fundamental para o surgimento do poder parlamentar na Inglaterra durante o século XVII e é particularmente importante para as organizações internacionais como as Nações Unidas e o Banco Mundial, que dependem de dotações governamentais para financiar partes substanciais de suas atividades. A accountability legal refere-se à exigência de que os agentes respeitem as regras formais e estejam preparados para justificar suas ações nesses termos em tribunais. O Mecanismo de Solução de Controvérsias da OMC, as operações do Tribunal de Haia sobre a ex-Iugoslávia e a criação de um novo Tribunal Penal Internacional ilustram as incursões que as concepções de accountability legal têm feito na política mundial (GRANT; KEOHANE, 2005). 
Accountability de mercado é uma categoria importante, porém menos familiar. Essa forma de accountability não é uma força abstrata chamada "mercado", mas para investidores e consumidores, sua influência é exercida total ou parcialmente por meio de mercados. Os consumidores podem recusar-se a comprar produtos de empresas com má reputação para padrões laborais ou outras práticas. Accountability dos pares, de acordo com Grant e Keohane (2005), surge como resultado da avaliação mútua das organizações pelos seus homólogos, como as ONGs que avaliam a qualidade da informação que recebem de outras ONGs e a facilidade de cooperar com elas.

Por fim, accountability da reputação pública é difundida porque a reputação está envolvida em todas as outras formas de accountability. É como um guarda-chuva que de certa forma permeia todas as outras formas de accountability. Superiores, conselhos fiscais, tribunais, fiscais, mercados e pares têm em conta a reputação dos agentes. A accountability da reputação pública deve ser aplicada a situações em que a reputação fornece um mecanismo de accountability, mesmo na ausência de outros mecanismos, ou em conjunto com eles (GRANT; KEOHANE, 2005).

\subsection{SCHMITTER A ACCOUNTABILITY POLÍTICA DE DEMOCRACIAS REAIS}

Schmitter (2007) estudou a accountability política em "democracias reais" e propôs adicionar uma terceira forma, além das propostas por O'Donnell (1991) de accountability vertical e horizontal. Esse autor sugere a adição da accountability oblíqua.

Essa forma de accountability seria exercida por diversas organizações da sociedade civil que não nomeiam candidatos nem disputam eleições, mas são capazes de mobilizar cidadãos para defender seus interesses e paixões no processo político. Esta ação coletiva é muito mais contínua e insidiosa no sentido de que eles procuram acesso independentemente do ciclo eleitoral e do local geográfico (SCHMITTER, 2007).

\subsection{BROWN E A ACCOUNTABILITY MÚTUA}

Brown (2007) pesquisou a accountability nas iniciativas de ação social de várias partes que buscam soluções para problemas sociais complexos, incertos e em constante mudança. O conceito de "iniciativas de ação social de várias partes" foi ilustrado por dois exemplos: um com foco na questão da influência nas políticas governamentais e internacionais, a partir caso da proposta de construção de uma usina geotérmica no Monte Apo, nas Filipinas, no início da década de 1980 e o outro com foco na resolução de problemas comerciais e industriais, a partir do caso do consórcio SEMATECH, de fabricação de semicondutores, cuja indústria estava em declínio.

Este autor sustenta que dois modelos conceituais embasam grande parte da pesquisa e discussão sobre accountability organizacional. Esses modelos seriam a teoria da agência e a teoria representativa.

A teoria da Agência tem foco nas relações entre os principais e seus agentes e, em particular, a accountability de um agente com os interesses e objetivos de um principal. 0 modelo baseia-se na teoria econômica neoliberal e sua principal preocupação é restringir o oportunismo de um agente cujos objetivos podem entrar em conflito com os dos principais.

A teoria representativa, ao contrário, concentra a atenção na accountability dos agentes públicos para seus eleitores. Este modelo tem raízes na teoria democrática. Concentra-se nas responsabilidades dos agentes eleitos perante os eleitores. Se os representantes não implementarem este mandato, as partes interessadas podem 
responsabilizá-los nas próximas eleições. Esses dois modelos seriam adequados, respectivamente, às empresas com fins lucrativos (teoria da agência) e à área governamental (representativa).

Além desses dois modelos, que segundo Brown (2007), não se adaptam às iniciativas de ação social de múltiplas partes, já que são focadas nas relações entre duas partes, o autor identifica a accountability mútua, que é definida como accountability entre os atores autônomos, que se baseia em valores e visões compartilhados e em relacionamentos de confiança e influência mútua.

\subsection{DENHARDT E DENHARDT E A NOVA ADMINISTRAÇÃO PÚBLICA}

Denhardt e Denhardt (2007) relacionam três modelos de administração pública, caracterizadas historicamente como: Velha Administração Pública (Old Public Administration), Nova Administração Pública (New Public Administration) e Novo Serviço Público (New Public Service). A cada um desses modelos é associada uma forma de accountability.

Para esses autores, a accountability característica da Velha Administração Pública tem uma visão formal, hierárquica e legal, sendo ainda o modelo mais familiar de accountability. Na Nova Administração Pública o foco da accountability passa a ser o cumprimento das normas de desempenho para produzir resultados. Já no Novo Serviço Público, as medidas de eficiência e os resultados continuam sendo importantes, mas não substituem outras expectativas em relação aos administradores públicos, como agir de forma responsável, ética e em conformidade com os princípios democráticos e do interesse público. Os ideais da cidadania e do interesse público estão no centro, sendo a accountability entendida de uma forma multifacetada e exigente em reconhecimento aos papéis complexos desempenhados pelos administradores públicos (DENHARDT; DENHARDT, 2007).

\subsection{WALDRON, ACCOUNTABILITY E DEMOCRACIA}

Considerando que accountability é uma ideia popular e que por vezes cientistas políticos parecem dar-lhe um aspecto cansativo e "clichê" da teoria democrática, Waldron (2014) ressalta que pode ser perigoso subestimar a sua importância e propõe três concepções de accountability: forense (Forensic-accountability), de agente (Agent-accountability) e de consumidor (Consumer-accountability).

Accountability forense denota a sujeição de uma pessoa a ter suas ações avaliadas por um tribunal, formal ou informal, com base em alguma norma estabelecida. Accountability de agente refere-se a direitos devidos por um agente ao seu principal, em que o principal pode exigir do agente a prestação de contas do trabalho que o agente tem feito em nome do responsável principal. Já accountability de consumidor denota que é desejável a uma organização considerar as opiniões ou preferências dos outros nas suas decisões. Este sentido de accountability é por vezes utilizado no mundo dos negócios e no governo, com entidades como hospitais, forças policiais e serviços de inspeção (WALDRON, 2014).

Waldron (2014) ressalta que accountability, muitas vezes, é identificada simplesmente com eleições ou com a "captura" daqueles que são cobrados por suas responsabilidades públicas, sem qualquer senso de sua contribuição para a compreensão da democracia. Desta forma, segundo esse autor, apenas a accountability de agente tem importância fundamental para a democracia. 


\subsection{SCHOMMER ET AL., ACCOUNTABILITY E A COPRODUÇÃO DE INFORMAÇÃO E CONTROLE}

Schommer et al. (2015) pesquisaram características da coprodução da informação e do controle sociopolítico sobre a gestão pública, nas relações entre observatórios sociais e órgãos de controle estatais. Os autores chegaram a uma classificação de accountability em quatro estágios: clássica, transversal, sistêmica e difusa.

Na accountability clássica, segundo Schommer et al. (2015), não há coprodução de informação e de controle e o nível de interação entre os mecanismos de controle social e institucional é baixa, assim como a capacidade de influência do controle social sobre as agências de controle institucional, sendo o Estado o responsável quase exclusivo por informação e controle. Na accountability transversal há coprodução esporádica e periférica de informação e de controle, a interação entre mecanismos de controle institucional e social mostra diferentes níveis de regularidade e a capacidade de influência do controle social sobre o sistema institucional de controle aumenta, mas o último mantém a sua estrutura. 0 aparelho de Estado continua sendo responsável pelas informações e controle, eventualmente compartilhando suas atividades com organizações da sociedade civil.

$\mathrm{Na}$ accountability sistêmica há coprodução de informação e controle de várias maneiras e em diferentes níveis de institucionalização, além do compromisso mútuo entre cidadãos e servidores públicos, que afetam continuamente os resultados das funções do Estado. $\mathrm{O}$ aparelho do Estado e suas responsabilidades assumem uma forma mais flexível. $\mathrm{Na}$ accountability difusa, informação e controle são produzidos por vários agentes, sem uma estrutura central e procedimentos padrão. A coprodução é exercida com baixo grau de institucionalização e não envolve necessariamente o aparelho de Estado. É o tipo ideal de accountability (SCHOMMER et al., 2015).

\section{ANÁLISE DOS TEXTOS}

Antes da explanação acerca do que foi identificado na análise dos textos, vale ressaltar que a amplitude temporal desse conjunto de artigos é de 35 anos. 0 artigo mais antigo é de 1981, ou seja, ainda na fase da gestação do que se passou a chamar de nova gestão pública (New Public Management). Este ano foi, inclusive, ano inicial do primeiro mandato de Ronald Reagan como presidente dos EUA, que junto com Margaret Thatcher, Primeira-Ministra do Reino Unido durante toda a década de 1980, representaram os principais promotores desta grande reforma neoliberal do Estado, implementada em grande parte dos países de todo o mundo. Já o artigo mais recente data de 2015. Durante esse período, os conceitos da nova gestão pública foram ao ápice em termos de popularidade e voltaram a ser altamente questionados por quem estuda organizações públicas (ECKERD; SNIDER, 2017).

Dos 16 artigos selecionados, metade tem foco em accountability no setor público, três abordam a questão de forma geral, sem focar em um determinado setor, dois focam na sociedade civil, e os outros três abordam accountability em realidades específicas (terceiro setor, global e antiguidade). Uma questão central na análise refere-se à importância de accountability na visão dos autores. Principalmente nos trabalhos que abordam a área pública, accountability é considerada um fenômeno importante, complexo e que carece de definição mais precisa. A exceção é o trabalho de O'Donnell (1991), que não discute o significado específico de accountability. Os trabalhos que não têm foco na área pública também relatam a importância e a indefinição do conceito, mas de forma menos enfática.

Ao se dividir os artigos por década em que foram publicados, tem-se uma evolução interessante sobre o ambiente em que se estuda accountability. Nos anos 1980, 100\% dos 
dois trabalhos foram baseados no ambiente da administração pública. Nos anos 1990, dos três trabalhos, 2 foram nesse ambiente, ou seja, 66,7\%. Nos anos 2000, dos 9 trabalhos, quatro tiveram foco na administração pública, o que dá um percentual de $44,4 \%$. Na década de 2010 , nenhum dos dois trabalhos teve como foco a administração pública. Tal evolução pode indicar uma tendência dos estudos sobre accountability estarem, ao longo do tempo, entendendo esse conceito de forma mais abrangente, adequado e adaptado a outras realidades que não somente a administração pública.

Em relação ao país das instituições às quais os autores estão vinculados, metade está nos EUA, quatro na Europa (sendo dois no Reino Unido, uma na Itália e uma com dois autores - Reino Unido e Espanha), dois na Austrália e dois no Brasil.

Quanto à análise de citação, a obra mais citada é o livro de Robert $D$. Behn chamado Rethinking Democratic Accountability, citado em cinco dos 16 trabalhos, ou seja, 31,3\%. Os textos de Carl Joachim Friedrich e de Herman Finer, respectivamente de 1940 e 1941 aparecem em segundo lugar dentre as obras mais citadas, com quatro citações cada, ou seja, $25 \%$. Ressalta-se que ambas foram citadas pelas mesmas quatro obras. Já as obras de Romzek e Dubnick (1987), Rosen (1989) e Keck e Sikkink (1997) tiveram três citações cada. Ressalta-se que a obra mais citada é relativamente recente, de 2001, enquanto as duas que dividem a segunda colocação são antigas, indicando um interesse histórico no assunto (Tabela 1).

Tabela 1 - Obras mais citadas

\begin{tabular}{clcc}
\hline Citações & \multicolumn{1}{c}{ Obra } & $\%$ \\
\hline 5 & BEHN, 2001 & 31,3 \\
\hline \multirow{2}{*}{4} & FRIEDRICH, 1940 & 25,0 \\
\cline { 2 - 3 } & FINER, 1941 & \multirow{2}{*}{16,7} \\
\cline { 2 - 3 } & ROMZEK; DUBNICK, 1987 & \\
\cline { 2 - 3 } & ROSEN, 1989 & & \\
\hline
\end{tabular}

Fonte: Autoria própria

Do conjunto dos 16 artigos analisados, o de Romzek e Dubnick (1987) é citado por outros três artigos e outros 4 (SMITH, 1981; KEARNS, 1994; ABRUCIO; LOUREIRO, 2004; KOPPELL, 2005) são citados por um artigo. Os outros não são citados pelo conjunto de artigos selecionado. Cabe ressaltar que O'Donnell tem um artigo de 1998 citado por dois artigos do conjunto. No presente estudo foi considerado o artigo de 1991.

De certa forma, surpreende que artigos que propõem uma classificação de accountability não referenciem trabalhos anteriores que propuseram algo parecido. Apenas cinco trabalhos citam outros do conjunto selecionado (KEARNS, 1994; SINCLAIR, 1995; KOPPELL, 2005; DENHARDT; DENHARDT, 2007; SCHOMMER et al., 2015). Ou seja, ao proporem uma tipologia de accountability, os autores parecem não pesquisar o que já foi feito com esse objetivo, pois não analisam nem criticam o que já foi feito nesse sentido, não permitindo, portanto, que se afirme que os autores não estivessem satisfeitos com as categorizações já realizadas.

Com o objetivo de melhor visualização da estrutura formada pelas obras analisadas, foi elaborado um sociograma a partir das referências bibliográficas dos mesmos. Desta forma, podem-se observar os artigos com maior grau de acoplamento bibliográfico, bem como os de maior centralidade na rede formada (FIGURA 1). 
Figura 1 - Artigos bibliograficamente acoplados

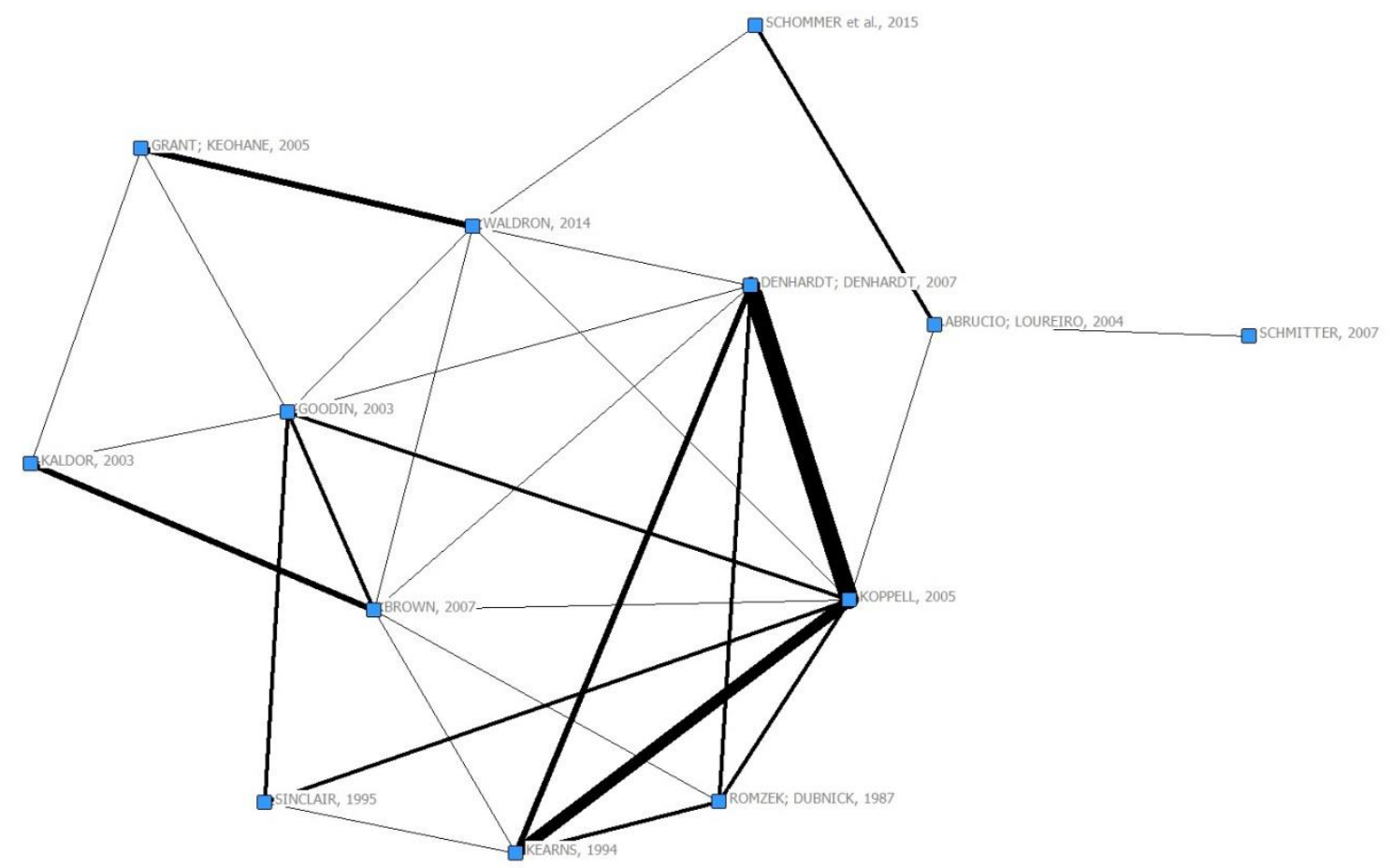

Fonte: Autoria própria

Das 16 obras, três não estão biliograficamente acopladas com nenhuma outra. Essas obras são Smith (1981), O'Donnell (1991) e Carmona e Ezzamel (2007). A obra com maior centralidade de grau é a de Koppel (2005), que é bibliograficamente acoplada com outras 8 obras. Em segundo lugar aparecem Brown (2007) e Goodin (2003) com 7 ligações cada (Tabela 2).

Tabela 2 - Centralidades de Grau e de proximidade

\begin{tabular}{lcc}
\hline \multicolumn{1}{c}{ Obra } & Degree (grau) & FreeClo (proximidade) \\
\hline KOPPELL, 2005 & 8 & 0,750 \\
\hline BROWN, 2007 & 7 & 0,667 \\
\hline GOODIN, 2003 & 7 & 0,667 \\
\hline DENHARDT; DENHARDT, 2007 & 6 & 0,632 \\
\hline WALDRON, 2014 & 6 & 0,632 \\
\hline KEARNS, 1994 & 5 & 0,545 \\
\hline ROMZEK; DUBNICK, 1987 & 4 & 0,522 \\
\hline ABRUCIO; LOUREIRO, 2004 & 3 & 0,522 \\
\hline SINCLAIR, 1995 & 3 & 0,522 \\
\hline KALDOR, 2003 & 3 & 0,480 \\
\hline GRANT; KEOHANE, 2005 & 3 & 0,462 \\
\hline SCHOMMER et al., 2015 & 2 & 0,462 \\
\hline SCHMITTER, 2007 & 1 & 0,353 \\
\hline
\end{tabular}

Fonte: Autoria própria

O trabalho de Koppell (2005), além de apresentar os maiores índices de centralidade de grau e de centralidade de proximidade, é o que forma as duas díades com maior número de citações em comum (TABELA 3). 
Tabela 3 - Artigos com maior grau de acoplamento bibliográfico

\begin{tabular}{lc}
\hline \multicolumn{1}{c}{ Dupla de obra (díade) } & Citações em comum \\
\hline KOPPELL, 2005 - DENHARDT; DENHARDT, 2007 & 7 \\
\hline KOPPELL, 2005 - KEARNS, 1994 & 5 \\
\hline DENHARDT; DENHARDT, 2007 - KEARNS, 1994 & 3 \\
\hline BROWN, 2007 - KALDOR, 2003 & 3 \\
\hline WALDRON, 2014 - GRANT; KEOHANE, 2005 & 3 \\
\hline KOPPELL, 2005 - ROMZEK; DUBNICK, 1987 & 2 \\
\hline KOPPELL, 2005 - GOODIN, 2003 & 2 \\
\hline KOPPELL, 2005 - SINCLAIR, 1995 & 2 \\
\hline DENHARDT; DENHARDT, 2007 - ROMZEK; DUBNICK, 1987 & 2 \\
\hline KEARNS, 1994 - ROMZEK; DUBNICK, 1987 & 2 \\
\hline SINCLAIR, 1995 - GOODIN, 2003 & 2 \\
\hline BROWN, 2007 - GOODIN, 2003 & 2 \\
\hline ABRUCIO; LOUREIRO, 2004 - SCHOMMER et al., 2015 & 2 \\
\hline
\end{tabular}

Fonte: Autoria própria

Foi levantado, também, o total de citações recebidas por cada uma das obras. Tal levantamento foi feito na base Google Acadêmico. A obra mais citada é a de Denhardt e Denhardt (2007) com 2108 citações, seguida por Grant e Keohane (2005) com 1568 citações, Romzek e Dubnick (1987) com 1205 e Sinclair (1995) com 1131 (Tabela 4).

Tabela 4 - Citações das obras estudadas

\begin{tabular}{|c|c|c|c|c|c|}
\hline Obras & $\begin{array}{l}\text { Citações } \\
\text { recebidas }\end{array}$ & $\%$ & $\begin{array}{c}\% \\
\text { acumulado }\end{array}$ & $\begin{array}{c}\text { Anos desde a } \\
\text { publicação }\end{array}$ & $\begin{array}{l}\text { Média } \\
\text { anual }\end{array}$ \\
\hline DENHARDT; DENHARDT, $2007^{(1)}$ & 2108 & $24,2 \%$ & $24,2 \%$ & 12 & 175,7 \\
\hline GRANT; KEOHANE, 2005 & 1568 & $18,0 \%$ & $42,3 \%$ & 14 & 112,0 \\
\hline ROMZEK; DUBNICK, 1987 & 1205 & $13,9 \%$ & $56,1 \%$ & 32 & 37,7 \\
\hline SINCLAIR, 1995 & 1131 & $13,0 \%$ & $69,1 \%$ & 24 & 47,1 \\
\hline O'DONNELL, 1991 & 764 & $8,8 \%$ & $77,9 \%$ & 28 & 27,3 \\
\hline KOPPELL, 2005 & 677 & $7,8 \%$ & $85,7 \%$ & 14 & 48,4 \\
\hline KEARNS, 1994 & 386 & $4,4 \%$ & $90,1 \%$ & 25 & 15,4 \\
\hline KALDOR, 2003 & 282 & $3,2 \%$ & $93,4 \%$ & 16 & 17,6 \\
\hline ABRUCIO; LOUREIRO, 2004 & 212 & $2,4 \%$ & $95,8 \%$ & 15 & 14,1 \\
\hline GOODIN, 2003 & 163 & $1,9 \%$ & $97,7 \%$ & 16 & 10,2 \\
\hline CARMONA; EZZAMEL, 2007 & 73 & $0,8 \%$ & $98,5 \%$ & 12 & 6,1 \\
\hline BROWN, 2007 & 38 & $0,4 \%$ & $99,0 \%$ & 12 & 3,2 \\
\hline SCHMITTER, 2007 & 38 & $0,4 \%$ & $99,4 \%$ & 12 & 3,2 \\
\hline SCHOMMER et al., 2015 & 20 & $0,2 \%$ & $99,6 \%$ & 4 & 5,0 \\
\hline WALDRON, 2014 & 16 & $0,2 \%$ & $100,0 \%$ & 5 & 3,2 \\
\hline SMITH, 1981 & 16 & $0,2 \%$ & $99,8 \%$ & 38 & 0,4 \\
\hline TOTAL & 8697 & & & & \\
\hline
\end{tabular}

(1) Número de citações referente ao livro todo, e não apenas ao capítulo sobre accountability. Fonte: Autoria própria, com base em dados coletados no Google Acadêmico em 25/07/2019.

As três obras mais citadas correspondem a mais da metade de citações do conjunto, e as seis mais citadas correspondem a pouco mais de $85 \%$. Todas essas seis obras mais citadas têm também os maiores índices na média de citações por ano. Com base nesses números, pode-se considerar que esses seis artigos são os que propõem classificações de accountability mais relevantes na literatura.

Apesar do artigo de Koppel (2005) ser o sexto artigo mais citado e o terceiro se for considerada a média anual, as outras obras com maior centralidade na rede de acoplamento bibliográfico não apresentam quantidades de citações relevantes, indicando que parece não haver relação entre as duas coisas. 


\section{RESULTADOS}

A análise dos trabalhos selecionados evidenciou a falta de consenso em relação ao conceito de accountability, bem como a multiplicidade de categorizações propostas por pesquisadores do tema.

A partir dessas categorizações identificadas na literatura, foi realizada uma nova categorização, com o objetivo de sintetizar as ideias propostas anteriormente, tentando abranger todas as categorias - ou o máximo possível - em um novo conjunto que consiga representar as ideias desenvolvidas. Após análise de cada categorização, seu contexto e suas características gerais e específicas, chegou-se a uma relação de 5 modelos de accountability. As categorias ora propostas são: Hierárquica, Política, Profissional, Legal e Mútua.

Para cada uma das categorias propostas pelos autores pesquisados, foi associada uma das cinco aqui propostas. Tal equivalência levou em conta as características e contexto de cada categoria (Quadro 1).

Quadro 1 - Categorizações de Accountability

\begin{tabular}{|c|c|c|c|c|c|}
\hline Autores & Contexto & País & \multicolumn{2}{|c|}{ Classificação } & Proposta (equivalência) \\
\hline \multirow{9}{*}{ SMITH, 1981} & \multirow{9}{*}{ Público } & \multirow{9}{*}{$\begin{array}{l}\text { Reino } \\
\text { Unido }\end{array}$} & \multicolumn{2}{|l|}{ Constitucional } & Política \\
\hline & & & \multicolumn{2}{|l|}{ Judicial } & Legal \\
\hline & & & \multicolumn{2}{|l|}{ Consultiva } & Política \\
\hline & & & \multicolumn{2}{|l|}{ Quase-judicial } & Legal \\
\hline & & & \multicolumn{2}{|l|}{ Processual } & Legal \\
\hline & & & \multicolumn{2}{|l|}{ Econômica } & Profissional \\
\hline & & & \multicolumn{2}{|l|}{ Comercial } & Política \\
\hline & & & \multicolumn{2}{|l|}{ Profissional } & Profissional \\
\hline & & & \multicolumn{2}{|l|}{ Descentralizada } & Profissional \\
\hline \multirow{4}{*}{$\begin{array}{c}\text { ROMZEK; } \\
\text { DUBNICK, } 1987\end{array}$} & \multirow{4}{*}{ Público } & \multirow{4}{*}{ EUA } & \multicolumn{2}{|l|}{ Burocrática } & Hierárquica \\
\hline & & & \multicolumn{2}{|l|}{ Legal } & Legal \\
\hline & & & \multicolumn{2}{|l|}{ Profissional } & Profissional \\
\hline & & & \multicolumn{2}{|l|}{ Política } & Política \\
\hline \multirow{2}{*}{$\begin{array}{c}\text { O'DONNELL, } \\
1991 \\
\end{array}$} & \multirow{2}{*}{ Público } & \multirow{2}{*}{ EUA } & \multicolumn{2}{|l|}{ Horizontal } & Política / Legal / Profis \\
\hline & & & \multicolumn{2}{|l|}{ Vertical } & Política \\
\hline \multirow{4}{*}{ KEARNS, 1994} & \multirow{4}{*}{$\begin{array}{l}\text { Terceiro } \\
\text { setor }\end{array}$} & \multirow{4}{*}{ EUA } & Da conformidade & & Legal \\
\hline & & & Negociada & & Mútua \\
\hline & & & Discricionária/profis & sional & Profissional \\
\hline & & & Antecipatória/posici & onada & Política \\
\hline & & & Política (ou democra & ática) & Política \\
\hline & & & Pública & & Política \\
\hline SINCLAIR, 1995 & Público & Austrália & Gerencial (ou financ & eira) & Hierárquica \\
\hline & & & Pessoal & & Mútua \\
\hline & & & Profissional & & Profissional \\
\hline & Sociedade & Reino & Moral & & Mútua \\
\hline KALDOR, 2003 & civil & Unido & Procedimental & & Legal \\
\hline & & & & Ações & Legal \\
\hline & & & Quanto ao Objeto & \begin{tabular}{|l|} 
Resultados \\
\end{tabular} & Política \\
\hline & & & & Intenções & Política \\
\hline GOODIN, 2003 & Geral & Austrália & & Hierárquico & Hierárquica \\
\hline & & & Quanto ao & Competitivo & Legal \\
\hline & & & Mecanismo & $\begin{array}{l}\text { Cooperativo em } \\
\text { rede }\end{array}$ & Mútua \\
\hline ABRUCIO; & & & Processo eleitoral & & Política \\
\hline LOUREIRO, & Público & Brasil & Controle institucion & al durante o mandato & Política \\
\hline 2004 & & & Regras estatais inter & temporais & Legal \\
\hline KOPPELL, 2005 & Público & EUA & Transparência & & Política \\
\hline
\end{tabular}

RGO - Revista Gestão Organizacional, Chapecó, v. 12, n. 2, p. 102-127, maio/ago. 2019. 


\begin{tabular}{|c|c|c|c|c|}
\hline & & & Sujeição & Legal \\
\hline & & & Controle & Hierárquica \\
\hline & & & Responsabilidade & Legal \\
\hline & & & Responsividade & Política \\
\hline \multirow{7}{*}{$\begin{array}{l}\text { GRANT; } \\
\text { KEOHANE, } \\
2005\end{array}$} & \multirow{7}{*}{ Global } & \multirow{7}{*}{ EUA } & Hierárquica & Hierárquica \\
\hline & & & Supervisora & Política \\
\hline & & & Fiscalizadora & Política \\
\hline & & & Legal & Legal \\
\hline & & & De mercado & Política \\
\hline & & & Por pares & Mútua \\
\hline & & & De reputação pública & Mútua \\
\hline \multirow{3}{*}{$\begin{array}{c}\text { CARMONA; } \\
\text { EZZAMEL, } 2007\end{array}$} & \multirow{3}{*}{$\begin{array}{l}\text { Antigui- } \\
\text { dade }\end{array}$} & \multirow{3}{*}{$\begin{array}{c}\text { Espanha / } \\
\text { Reino } \\
\text { Unido } \\
\end{array}$} & Do indivíduo para o indivíduo & Mútua \\
\hline & & & Do indivíduo para o estado & Legal \\
\hline & & & Do estado para o indivíduo & Política \\
\hline \multirow{3}{*}{$\begin{array}{l}\text { SCHMITTER, } \\
2007\end{array}$} & \multirow{3}{*}{ Público } & \multirow{3}{*}{ Itália } & Horizontal & Política / Legal / Profis \\
\hline & & & Vertical & Política \\
\hline & & & Oblíqua & Política \\
\hline \multirow{3}{*}{ BROWN, 2007} & \multirow{3}{*}{ Geral } & \multirow{3}{*}{ EUA } & Agência & Hierárquica \\
\hline & & & Representativa & Política \\
\hline & & & Mútua & Mútua \\
\hline \multirow{3}{*}{$\begin{array}{c}\text { DENHARDT; } \\
\text { DENHARDT, } \\
2007\end{array}$} & \multirow{3}{*}{ Público } & \multirow{3}{*}{ EUA } & Velha Administração Pública & Hierárquica / Legal \\
\hline & & & Nova Administração Pública & Política \\
\hline & & & Novo Serviço Público & Política \\
\hline \multirow{3}{*}{$\begin{array}{l}\text { WALDRON, } \\
2014\end{array}$} & \multirow{3}{*}{ Geral } & \multirow{3}{*}{ EUA } & Forense & Legal \\
\hline & & & De agente & Política \\
\hline & & & De consumidor & Política / Mútua \\
\hline \multirow{4}{*}{$\begin{array}{c}\text { SCHOMMER et } \\
\text { al., } 2015\end{array}$} & \multirow{4}{*}{$\begin{array}{c}\text { Sociedade } \\
\text { civil }\end{array}$} & \multirow{4}{*}{ Brasil } & Clássica & Hierárquica \\
\hline & & & Transversal & Hierárquica \\
\hline & & & Sistêmica & Política \\
\hline & & & Difusa & Mútua \\
\hline
\end{tabular}

Fonte: Autoria própria

Como se pode observar, a tipologia proposta busca uniformizar as propostas anteriores em quatro categorias, de forma que consiga abranger todas as dimensões estudadas nos estudos analisados.

A accountability hierárquica se refere, assim como em Goodin (2003), à accountability que se utiliza da autoridade hierárquica de comando e controle. Refere-se, também, às estruturas burocráticas do governo e de grandes organizações que são, em última análise, fortemente hierarquizadas.

A accountability política se caracteriza como a que é exercida pelo eleitor em relação ao gestor público eleito, mas também inclui situações em que o principal exerce seu poder em relação ao agente, ou seja, é a resposta do agente ao principal.

A accountability profissional tem como principal característica, assim como em Smith (1981) a "propriedade do conhecimento", ou seja, se relaciona com situações em que é exigido conhecimento técnico sobre um assunto. Isso vale tanto para a área pública quanto para a privada.

A accountability legal, como não poderia deixar de ser, se refere à exigência de se cumprir a legislação, as regras formais e obrigações contratuais.

Por último, a accountability mútua, termo utilizado por Brown (2007), que se refere às relações entre atores autônomos, que compartilham confiança e influência mútua.

Conforme já explicitado, para cada uma das categorias presentes nos trabalhos analisados, foi atribuída uma ou mais dessas cinco categorias propostas no presente estudo, 
na tentativa de fazer uma síntese das diversas tipologias encontradas na literatura. Evidentemente não é possível que as categorias propostas no presente estudo consigam representar todas as nuances das várias categorias consideradas equivalentes. $\mathrm{O}$ que se tentou foi uma simplificação geral das várias classificações, de forma que possam ser consideradas em diversos contextos diferentes. A ideia não é substituir as categorizações já feitas. Certamente cada uma delas se adequa melhor a várias situações e realidades específicas. A categorização aqui proposta visa uma tipologia geral, que ajude a identificação de accountability em diferentes contextos.

A partir dessa tipologia proposta, entende-se que accountability pode ser entendida como o processo que exige transparência, prestação de contas e responsabilização de entes públicos e privados, a partir do controle e fiscalização internos e/ou externos.

\section{CONSIDERAÇÕES FINAIS}

Vários autores assumem o dissenso generalizado acerca do conceito de accountability, e não são apenas autores de língua portuguesa. Dessa forma, ainda que não vivenciemos de forma madura, cotidianamente no Brasil, os conceitos que permeiam a noção de accountability, talvez não seja esse o motivo principal para não termos uma palavra que traduza todo o universo que representa tal noção, até porque não há consenso acerca dos limites desse universo. Muito se discute, atualmente, o que é exatamente accountability. Quais os parâmetros? O que não é accountability? Quando surgiu a accountability? Onde pode ser identificado? Existem níveis de accountability? Tais questões permeiam alguns dos estudos apresentados no presente artigo, mas as respostas ainda estão longe de serem um consenso. Apesar disso, existem estudos onde se identificam tipos de accountability no antigo Egito e antiga Mesopotâmia, e estudos sobre a accountability na Atenas Clássica e em cidades medievais. Sem entrar no mérito e independente da pertinência, justificativa e relevância de tais estudos, se existia algum tipo de accountability na antiguidade e na idade média que permita que se faça uma classificação de seus tipos, a forma como tal conceito tem sido utilizado atualmente, principalmente em relação à tradução para a língua portuguesa, precisa ser melhor estudada.

Chama a atenção a quantidade de categorizações desenvolvidas pelos pesquisadores da área, que necessitam dividir/desmembrar o conceito e/ou as práticas de accountability, para então classificá-las e estudá-las. Possivelmente essa prática ocorre em função da indefinição do conceito. De qualquer forma, os pesquisadores não parecem se contentar com as várias categorizações já feitas, pois novas propostas continuam sendo apresentadas. No entanto, o desenvolvimento de novas categorizações de accountability na área pública, conforme foi visto, tem diminuído com o passar dos tempos. Uma possibilidade para isso é que o interesse pelo assunto na área pública tenha dado lugar a análises mais abrangentes, sendo realizadas, então, categorizações em áreas específicas. Outra possibilidade é que as categorizações feitas anteriormente já dão conta de ajudar a explicar os fenômenos relacionados à accountability pública. Fortalece esse entendimento o fato de, das seis obras mais citadas, cinco tiveram foco na accountability pública, o que demonstra que essas classificações têm sido, no mínimo, consultadas. No entanto, vale ressaltar que essas obras são pouco citadas pelos nos trabalhos que propõem uma nova classificação, indicando, possivelmente, que as novas classificações são propostas sem uma análise crítica do que já se produziu nesse sentido.

Existe também uma dimensão ideológica nesses estudos. A accountability se dá em um ambiente de disputa política, no qual alguns interesses são privilegiados em detrimento de 
outros, mesmo em ambientes não governamentais. Os processos de transparência, responsabilização e os demais seguem uma lógica de disputa de poder que é refletida na epistemologia desses estudos e é uma dimensão dos estudos epistemológicos que não foi tratada no presente artigo, mas que merece estudo mais aprofundado.

\section{REFERÊNCIAS}

ABRUCIO, F. L.; LOUREIRO, M. R. Finanças públicas, democracia e accountability: debate teórico e o caso brasileiro. In: ARVATE, P. R.; BIDERMAN, C. Economia do setor público no Brasil. Rio de Janeiro: Elsevier, 2004. p. 75-102.

ACKERMAN, J. Co-governance for accountability: beyond "exit" and "voice". World Development, v. 32, n. 3, p. 447-463, 2004. DOI: https://doi.org/10.1016/i.worlddev.2003.06.015

BEHN, R. D. Rethinking Democratic Accountability. Washington, DC: Brookings Institution, 2001.

BERNARDES, M. B.; SANTOS, P. M.; ROVER, A. J. Ranking das prefeituras da região Sul do Brasil: uma avaliação a partir de critérios estabelecidos na Lei de Acesso à Informação. Revista de Administração Pública, Rio de Janeiro, v. 49, n. 3, p. 761-792, 2015. DOI: http://dx.doi.org/10.1590/0034-7612119279.

BEVIR, M. Democratic Governance: A Genealogy. Local Government Studies, v. 37, n. 1, p. 317, 2011. DOI: https://doi.org/10.1080/03003930.2011.539860

BOUWMAN, R.; VAN THIEL, S.; VAN DEEMEN, A.; ROUWETTE, E. Accountability and coalitions: Evidence from a negotiation experiment. Public Administration Review, v. 78, $\mathrm{n}$. 1, p. 37-47, 2018. DOI: https://doi.org/10.1111/puar.12858.

BOVENS, M. Two Concepts of Accountability: Accountability as a Virtue and as a Mechanism. West European Politics, v. 33, n. 5, p. 946-967, 2010. DOI:

https://doi.org/10.1080/01402382.2010.486119.

BROWN, L. D. Multiparty social action and mutual accountability. In: EBRAHIM A.; WEISBAND, E. Global Accountability and Moral Community. Cambridge: Cambridge University Press, 2007. p. 5-31.

BRYER, R. A. The history of accounting and the transition to capitalism in England. Part one: theory. Accounting, Organizations and Society, v. 25, n. 2, p. 131-162, 2000. DOI: https://doi.org/10.1016/s0361-3682(99)00032-x.

BUSUIOC, M.; LODGE, M. Reputation and accountability relationships: Managing accountability expectations through reputation. Public Administration Review, v. 77, n. 1, p. 91-100, 2017. DOI: https://doi.org/10.1111/puar.12612. 
CAMPAGNONI, M.; CARVALHO, R. D.; LYRIO, M. V. L.; LUNKES, R. J.; ROSA, F. S. Transparência no Poder Legislativo Municipal: uma Análise dos Portais Eletrônicos das Câmaras de Vereadores das Capitais Brasileiras. Revista Gestão Organizacional, Chapecó, v. 9, n. 1, p. 21-42, 2016. DOI: http://dx.doi.org/10.22277/rgo.v9i1.2934

CAMPOS, A. M. Accountability: quando poderemos traduzi-la para o português? Revista de Administração Pública, Rio de Janeiro, v. 24, n. 2, p. 30-50, 1990. Disponível em:

http://bibliotecadigital.fgv.br/ojs/index.php/rap/article/view/9049. Acesso em: 8 jul. 2019.

CARMONA, S.; EZZAMEL, M. Accounting and accountability in ancient civilizations:

Mesopotamia and ancient Egypt. Accounting, Auditing \& Accountability Journal, v. 20, n. 2, p. 177-209, 2007. DOI: https://doi.org/10.1108/09513570710740993

CENEVIVA, R. Accountability: novos fatos e novos argumentos - uma revisão da literatura recente. In: ENCONTRO DE ADMINISTRAÇÃO PÚBLICA E GOVERNANÇA DA ANPAD, 2., 2006, São Paulo. Anais [...]. Rio de Janeiro: ANPAD, 2006. p. 1-17.

CUMBE, L. L.; INÁCIO, H. The impact of external audit on the accountability of the common fund of the Mozambique National Institute of Statistics. Managerial Auditing Journal, v. 33, n. 6/7, p. 538-557, 2018. DOI: https://doi.org/10.1108/MAJ-01-2017-1500.

DABÓS, Marcelo P.; GANTMAN, Ernesto R.; RODRÍGUEZ, Carlos J. Fernández. The Prestige of Social Scientists in Spain and France: An Examination of Their h-Index Values Using Scopus and Google Scholar. Minerva, v. 57, n. 1, p. 47-66, 2019. DOI:

https://doi.org/10.1007/s11024-018-9358-0.

DENHARDT, J. V.; DENHARDT, R. B. The new public service: serving, not steering. Expanded edition. Nova York: M. E. Sharp, 2007.

ECKERD, A.; SNIDER, K. Does the program manager matter? New Public Management and defense acquisition. The American Review of Public Administration, v. 47, n. 1, p. 36-57, 2017. DOI: https://doi.org/10.1177/0275074015596376.

FILGUEIRAS, F. Além da transparência: accountability e política da publicidade. Lua Nova, São Paulo, v. 84, p. 65-94, 2011. DOI: http://dx.doi.org/10.1590/S0102-64452011000300004.

FINER, H. Administrative Responsibility and Democratic Government. Public Administration Review, v. 1, p. 335-350, 1941. DOI: https://doi.org/10.2307/972907.

FRIEDRICH, C. J. Public Policy and the Nature of Administrative Responsibility. In: FRIEDRICH, C.; MASON, E. S. (eds.). Public Policy. Cambridge: Harvard University Press, 1940. p. 3-24.

GIL, A. C. Métodos e Técnicas de Pesquisa Social. 6. ed. São Paulo, Atlas, 2008.

GODFREY, A.; HOOPER, K. Accountability and decision-making in feudal England: Domesday Book revisited. Accounting History, v. 1, n. 1, p. 35-54, 1996. DOI:

https://doi.org/10.1177/103237329600100103. 
GOODIN, R. E. Democratic accountability: The distinctiveness of the third sector. European Journal of Sociology, v. 44, n. 03, p. 359-396, 2003. DOI:

https://doi.org/10.1017/s0003975603001322.

GRACILIANO, E. A.; MOREIRA FILHO, J. C.; NUNES, A de P.; PONTES, F. C de M.; ZAMPA, F. F. Accountability na administração pública federal: contribuição das auditorias operacionais do TCU. Pensar Contábil, Rio de Janeiro, v. 12, n. 47, p. 43-51, 2010. Disponível em: http://www.atena.org.br/revista/ojs-2.2.3-08/index.php/pensarcontabil/article/view/750. Acesso em: 8 jul. 2019.

GRANEHEIM, U. H.; LINDGREN, B.-M.; LUNDMAN, B. Methodological challenges in qualitative content analysis: A discussion paper. Nurse Education Today, v. 56, p. 29-34, 2017. DOI: https://doi.org/10.1016/j.nedt.2017.06.002.

GRANT, R. W.; KEOHANE, R. O. Accountability and abuses of power in world politics. American political science review, v. 99, n. 1, p. 29-43, 2005. DOI: https://doi.org/10.1017/s0003055405051476.

GUSENBAUER, M. Google Scholar to overshadow them all? Comparing the sizes of 12 academic search engines and bibliographic databases. Scientometrics, v. 118, n. 1, p. 177214, 2019. DOI: https://doi.org/10.1007/s11192-018-2958-5.

HALL, A. T.; FRINK, D. D.; BUCKLEY, M, R. An accountability account: A review and synthesis of the theoretical and empirical research on felt accountability. Journal of Organizational Behavior, v. 38, n. 2, p. 204-224, 2017. DOI: https://doi.org/10.1002/job.2052.

KALDOR, M. Civil society and accountability. Journal of Human Development, v. 4, n. 1, p. 527, 2003. DOI: https://doi.org/10.1080/1464988032000051469.

KEARNS, K. P. The Strategic Management of Accountability in Nonprofit Organizations: An Analytical Framework. Public Administration Review, v. 54, n. 2, p. 185-192, 1994. DOI: https://doi.org/10.2307/976528.

KECK, M.; SIKKINK, K. Activists Beyond Borders: Advocacy Networks in International Politics. Ithaca, NY: Cornell University Press, 1997.

KOOP, C.; HANRETTY, C. Political independence, accountability, and the quality of regulatory decision-making. Comparative Political Studies, v. 51, n. 1, p. 38-75, 2018. DOI: https://doi.org/10.1177/0010414017695329.

KOPPELL, J. G. S. Pathologies of accountability: ICANN and the challenge of "multiple accountabilities disorder". Public Administration Review, v. 65, n. 1, p. 94-108, 2005. DOI: https://doi.org/10.1111/j.1540-6210.2005.00434.x.

MARTIN, L. L.; FRAHM, K. The Changing Nature of Accountability in Administrative Practice. Journal of Sociology \& Social Welfare, v. 37, n. 1, p. 137-148, 2010. Disponível em: https://scholarworks.wmich.edu/jssw/vol37/iss1/8. Acesso em: 8 jul. 2019. 
MARTÍN-MARTÍN, A.; ORDUNA-MALEA; E., THELWALL, M.; LÓPEZ-CÓZAR, E. D. Google Scholar, Web of Science, and Scopus: A systematic comparison of citations in 252 subject categories. Journal of Informetrics, v. 12, n. 4, p. 1160-1177, 2018. DOI: https://doi.org/10.1016/j.joi.2018.09.002.

MEDEIROS, A. K. de; CRANTSCHANINOV, T. I.; SILVA, F. C. da. Estudos sobre accountability no Brasil: meta-análise de periódicos brasileiros das áreas de administração, administração pública, ciência política e ciências sociais. Revista de Administração Pública, Rio de Janeiro, v. 47, n. 3, p. 745-775, 2013. DOI: http://dx.doi.org/10.1590/S0034-76122013000300010.

MULGAN, R. Comparing accountability in the public and private sectors. Australian Journal of Public Administration, v. 59, n. 1, p. 87-97, 2000. DOI: https://doi.org/10.1111/14678500.00142 .

MYINT, U. Corruption: causes, consequences and cures. Asia pacific development journal, v. 7, n. 2, p. 33-58, 2000. Disponível em: https://www.unescap.org/sites/default/files/apdj-7-22-Myint.pdf. Acesso em: 20 jul. 2019.

NAKAGAWA, M.; RELVAS, T. R. S.; DIAS FILHO, J. M. Accountability: a razão de ser da contabilidade. Revista de Educação e Pesquisa em Contabilidade, Brasília, v. 1, n. 3, p. 83100, 2007. DOI: https://doi.org/10.17524/repec.v1i3.17.

O’DONNELL, G. Accountability horizontal e novas poliarquias. Lua Nova, São Paulo, n. 44, p. 27-54, 1998. DOI: https://doi.org/10.1590/s0102-64451998000200003.

O’DONNELL, G. Democracia Delegativa? Novos Estudos CEBRAP, São Paulo, n. 31, p. 25-40, 1991.

OLSEN, J. P. Accountability democrática, ordem política e mudança: explorando processos de accountability em uma era de transformação europeia. Brasília: ENAP, 2018.

PAPENFUß, U.; SCHAEFER, C. Improving public accountability by aligning reporting to organizational changes in public service provision-an empirical Internet study of all Austrian, German and Swiss towns and states from an agency-theory perspective. International Review of Administrative Sciences, v. 76, n. 3, p. 555-576, 2010. DOI: http://doi.org/10.1177/0020852310372451.

PRINS A.; COSTAS, R.; VAN LEEUWEN, T.; WOUTERS, P. Using Google Scholar in research evaluation of humanities and social science programs: A comparison with Web of Science data. Research Evaluation, v. 25, n. 3, p. 264-270, 2016. DOI: http://doi.org/10.1093/reseval/rvv049.

ROCHA, A. C. Accountability na Administração Pública: Modelos Teóricos e Abordagens. Contabilidade, Gestão e Governança, Brasília, v. 14, n. 2, p. 82-97, 2011. Disponível em: https://www.revistacgg.org/contabil/article/view/314. Acesso em: 20 jul. 2019. 
ROCHA, A. C. A realização da accountability em pareceres prévios do Tribunal de Contas de Santa Catarina. Revista de Administração Pública, v. 47, n. 4, p. 901-926, 2013. DOI: https://doi.org/10.1590/s0034-76122013000400005.

ROMZEK, B. S.; DUBNICK, M. J. Accountability in the Public Sector: Lessons from the Challenger Tragedy. Public Administration Review, v. 47, n. 3, p. 227-238, 1987. DOI: https://doi.org/10.2307/975901.

ROSEN, B. Holding Government Bureaucracies Accountable. 2d ed. New York: Praeger, 1989.

SCHMITTER, P. C. Political accountability in 'real-existing' democracies: meaning and mechanisms. Instituto Universitario Europeo. Firenze, Italia, Genaio, 2007. Disponível em: https://www.eui.eu/Documents/DepartmentsCentres/SPS/Profiles/Schmitter/PCSPoliticalAc countabilityJan07.pdf. Acesso em: 8 jul. 2019.

SCHOMMER, P. C.; ROCHA, A. C.; SPANIOL, E. L.; DAHMER; J.; SOUSA; A. D. Accountability and co-production of information and control: social observatories and their relationship with government agencies. Revista de Administração Pública, Rio de Janeiro, v. 49, n. 6, p. 1375-1400, 2015. DOI: https://doi.org/10.1590/0034-7612115166.

SILVA, D. D.; GRÁCIO, M. C. C. Índice h de Hirsch: análise comparativa entre as bases de dados Scopus, Web of Science e Google Acadêmico. Em Questão, Porto Alegre, v. 23, Edição Especial 5 EBBC, p. 196-212, 2017. DOI: http://dx.doi.org/10.19132/1808-5245230.196-212.

SINCLAIR, A. The chameleon of accountability: Forms and discourses. Accounting, organizations and Society, v. 20, n. 2-3, p. 219-237, 1995. DOI:

https://doi.org/10.1016/0361-3682(93)e0003-y.

SMITH, B. C. Control in British Government: a problem of accountability. Policy Studies Journal, v. 9, n. 8, p. 1163-1174, 1981. DOI: https://doi.org/10.1111/j.15410072.1981.tb01229.x.

SOLL, J. The reckoning: Financial accountability and the rise and fall of nations. Philadelphia: Basic Books, 2014.

THICK, A. Accounting in the late medieval town: the account books of the stewards of Southampton in the fifteenth century. Accounting, Business \& Financial History, v. 9, n. 3, p. 265-290, 1999. DOI: https://doi.org/10.1080/095852099330214.

WALDRON, J. Accountability: Fundamental to Democracy. New York University Public Law and Legal Theory Working Papers. Paper 462, 2014. DOI:

https://dx.doi.org/10.2139/ssrn.2410812.

XAVIER, R. S. Accountability e as suas múltiplas abordagens: um balanço teórico. In:

ENCONTRO NACIONAL DA ANP AD, 35., 2011, Rio de Janeiro. Anais [...]. Rio de Janeiro: ANPAD, 2011. p. 1-14. Disponível em: 
http://www.anpad.org.br/ anpad/eventos.php?cod_evento=1\&cod_edicao_subsecao=736 \&cod_evento_edicao=58\&cod_edicao_trabalho=13077. Acesso em: Acesso em: 8 jul. 2019.

ZUPIC, I.; ČATER, T. Bibliometric methods in management and organization. Organizational Research Methods, v. 18, n. 3, p. 429-472, 2015. DOI:

https://doi.org/10.1177/1094428114562629. 